\title{
Modelo de tradução de imagens estáticas em imagens táteis: avaliação e testagem com mapas táteis
} Translation model of static images into tactile images: evaluation and testing with tactile maps

\author{
Emilia Christie Picelli Sanches \& Juliana Bueno
}

acessibilidade, cegueira, imagens táteis, impressão 3D

\begin{abstract}
O acesso igualitário a todos os níveis de educação, pelas pessoas com deficiência, é um dos objetivos a serem alcançados pela sociedade. Sendo assim, este acesso ao conteúdo educacional e visual é um direito das pessoas cegas e deve ser cumprido. Uma das formas de adaptar o material visual ao cego é através de imagens táteis, área em que o design da informação pode se inserir e auxiliar. O propósito deste artigo, então, é apresentar um modelo de tradução de imagens estáticas em imagens táteis, e demonstrar a avaliação e testagem através de mapas táteis. Para isso, o artigo divide-se em seis tópicos: (1) introdução ao tema; (2) breve revisão teórica sobre imagens táteis; (3) modelo de tradução; (4) impressão 3D de mapas táteis; (5) teste de compreensão e; (6) considerações finais. Os resultados dos testes de compreensão realizados com voluntários cegos demonstraram pontos positivos e melhorias ao modelo de tradução, o qual foi atualizado com novas sugestões e recomendações.
\end{abstract}

accessibility, blindness, tactile images, 3D printing

The equal access to all educational levels, for the people with disabilities, is one of the goals to be reached by society. Thus, this access to visual educational content by people who are blind is a right and must be fulfilled. One of the ways to adapt visual material for the blind is through tactile images, area where the information design can be inserted and assist. The purpose of this paper is to present a translation model of static images into tactile images, and to demonstrate the evaluation and testing with tactile maps. In order to execute it, the paper is divided into six topics: (1) introduction to the subject; (2) brief theoretical review of tactile images; (3) translation model; (4) 3D printing of tactile maps; (5) comprehension test and; (6) final considerations. The result from the comprehension tests done with blind volunteers demonstrated positive outcomes and improvements to the translation model, which was updated with new suggestions and recommendations.

\section{Introdução}

Tratando-se de pessoas com deficiência, a Organização das Nações Unidas (ONU), através de dados da Organização Mundial de Saúde, estima que uma em cada sete pessoas no mundo possui algum tipo de deficiência - cerca de 1 bilhão (ONU, 2016). Destas, calcula-se que $80 \%$ vivem em países em desenvolvimento (ONU, 2016), caso do Brasil. De acordo com o Instituto Brasileiro de Geografia e Estatística (IBGE, 2010), a deficiência visual é a mais recorrente no país, sendo maioria dentre outras deficiências (visual, auditiva, mental/intelectual e motora). Das pessoas com deficiência visual, cerca de 500 mil são cegas (IBGE, 2010).

Em um esforço de se construir um mundo sustentável, equitativo e inclusivo, a ONU determinou 17 Objetivos de Desenvolvimento Sustentável, para serem implementados pelos países até 2030. Entre esses objetivos, são cinco os que mencionam diretamente pessoas com deficiência (ONU, 2015; ONU, 2019):

- Objetivo 4: assegurar a educação inclusiva, equitativa e de qualidade, e promover oportunidades de aprendizagem ao longo da vida para todos;

- Objetivo 8: promover o crescimento econômico sustentado, inclusivo e sustentável, emprego pleno e produtivo e trabalho decente para todos;

Anais do 9 CIDI e 9 CONGIC

Luciane Maria Fadel, Carla Spinillo, Anderson Horta,

Cristina Portugal (orgs.)

Sociedade Brasileira de Design da Informação - SBDI

Belo Horizonte | Brasil | 2019

ISBN 978-85-212-1728-2
Proceedings of the 9th CIDI and 9th CONGIC

Luciane Maria Fadel, Carla Spinillo, Anderson Horta, Cristina Portugal (orgs.)

Sociedade Brasileira de Design da Informação - SBDI Belo Horizonte | Brazil | 2019

ISBN 978-85-212-1728-2 
- Objetivo 10: reduzir a desigualdade dentro dos países e entre eles;

- Objetivo 11: tornar as cidades e os assentamentos humanos inclusivos, seguros, resilientes e sustentáveis; e

- Objetivo 17: fortalecer os meios de implementação e revitalizar a parceria global para o desenvolvimento sustentável.

Sendo o foco deste artigo a Educação, evidencia-se o Objetivo 4, onde um dos seus planos de ação é de "eliminar disparidades de gênero na educação e garantir acesso igualitário em todos os níveis de educação e treinamento vocacional para vulneráveis, incluindo pessoas com deficiência, indígenas e crianças em situação vulnerável" (ONU, 2015, tradução e grifo nossos).

Para Sassaki (2010), a inclusão escolar tem por objetivo constituir um sistema onde todas as necessidades são consideradas, sejam elas dos estudantes, professores ou outros profissionais envolvidos. Agregando a esta ideia, Mantoan (2003, p.25) afirma que uma escola inclusiva deve oferecer "alternativas que contemplem a diversidade, além de recursos de ensino e equipamentos especializados que atendam a todas as necessidades educacionais dos educandos, com ou sem deficiências, mas sem discriminações". À vista disso, entende-se que a Educação deve ser acessível para todos, mesmo que as informações cheguem até o estudante de formas, equipamentos ou mídias diferentes.

Ao se referir à Educação de uma pessoa cega, os materiais didáticos visuais são adaptados aos sentidos táteis e/ou auditivos. É no âmbito da adaptação e tradução de materiais para pessoas cegas que este artigo traça o paralelo entre acessibilidade e o design da informação. Para Waller (2016, p.35, tradução nossa), o design da informação é "a aplicação de um processo de design em uma tarefa de informar pessoas". Em complemento, o International Institute of Information Design - IID (2019) entende o design da informação como uma área que atende as necessidades informacionais dos sujeitos, através do planejamento, definição e modelagem do conteúdo informacional e seu ambiente.

Entende-se, além disso, que o design da informação tem sua atuação atrelada à linguagem visual (Horn, 1999), seja ela verbal, pictórica ou esquemática (Twyman, 1982). Porém, quando o receptor da mensagem é uma pessoa cega, as informações visuais necessitam ser modeladas para se adaptar aos sentidos auditivos e/ou táteis, através de: audiodescrições, Braille, imagens táteis, entre outros. Assim, é imprescindível levar em consideração as particularidades dos sentidos do público cego e a essência da informação.

Com isso em mente e, tendo como premissa o Design Universal (NCSU, 1997), foi elaborado um modelo de tradução de imagens estáticas em imagens táteis, para serem impressas em 3D (Sanches, 2018), apresentando como fundamento o acesso igualitário ao conteúdo educacional por pessoas cegas e videntes. O modelo de tradução foi desenvolvido, posteriormente validado com designers e, também, com cegos. Tendo em vista que a validação com os designers foi relatada em publicação anterior (Sanches, Macedo \& Bueno, 2017), os objetivos deste artigo são:

- Apresentar brevemente a tradução e impressão 3D de mapas táteis do Estado do Paraná - tendo na amostra um mapa geográfico, um mapa de rotas, um mapa estatístico e um mapa estatístico de rotas (Engelhardt, 2002);

- Detalhar o teste de compreensão dos mapas, dividido entre teste piloto e teste principal, realizado com 10 cegos;

- Discutir os resultados dos testes e as contribuições ao modelo de tradução.

Sendo assim, o artigo inicia com uma breve revisão teórica sobre imagens táteis. Depois, descreve rapidamente a construção do modelo de tradução inicial, gerado a partir de recomendações e diretrizes de acessibilidade encontradas na literatura, e testado com designers para ajustes de conteúdo e estrutura. Em seguida, relata o processo de coleta e escolha de mapas estáticos do portal Dia a Dia Educação, a modelagem digital dos mapas táteis (através dos requisitos gerados pelo modelo de tradução) e a impressão 3D dos mesmos. No tópico seguinte, descreve os testes de compreensão realizados com os cegos. Por fim, realiza considerações finais sobre o processo. 


\section{Imagens táteis}

O tato é um dos sentidos usados pelas pessoas cegas para interpretar o mundo ao seu redor, pois, como discorre Duarte (2011, p. 78), "aquele que não vê precisa usar muito frequentemente a modalidade tátil para reconhecer objetos". A percepção tátil ocorre de forma sequencial-temporal e é fragmentada, limitada ao "tempo que as mãos gastam para percorrer a sua forma" (Duarte, 2011, p.76). Porém, como avalia Nogueira (2007), a identificação de objetos por meio do tato requer o desenvolvimento de uma sensibilidade tátil, para de fato entendê-los. É importante que o exercício dessa percepção tátil seja estimulado desde criança (Duarte, 2011), ou logo que se adquire a cegueira.

Uma das formas de estímulo da percepção tátil e aquisição de novos conhecimentos é fazer uso das imagens táteis. Como o próprio nome sugere, são imagens com relevo e volume para que pessoas cegas possam compreender e aprender informações visuais. Estão frequentemente presentes em livros didáticos para a alfabetização de pessoas cegas, na tradução tátil de obras de arte, e em disciplinas como História, Geografia e Biologia (Loch, 2008; Valente, 2009).

O processo de fabricação dessas imagens táteis é variado, a exemplo:

- Artesanal: não há técnica nem materiais específicos. Podem ser usados, por exemplo, madeira, isopor, barbante, cola, etc.;

- Termoformagem: chapa de material termoplástico, que por vácuo ou calor, reproduz os relevos da imagem através de um molde pré-existente (Gual, Puyuelo \& Lloveras, 2014);

- Impressão em relevo: impressão em papel microencapsulado, onde a tinta preta impressa sobre o papel reage ao calor, criando o relevo (Loch, 2008; Gual et al., 2014);

- Impressão 3D: tecnologia de prototipagem rápida onde a impressão é feita por adição de material em camadas, processo em expansão na criação de imagens e mapas táteis. O principal argumento para o uso da impressão 3D como meio produtivo é a possibilidade de se usar elementos tridimensionais.

O uso de imagens táteis como recurso acessível a imagens estáticas requer, além da escolha do processo de fabricação, o planejamento de sua tradução para que a imagem tátil mantenha o mesmo significado e seja compreensível aos cegos. Há também que se refletir sobre quando a tradução tátil é necessária. Para Gruenwald (2014), imagens que possuam conceitos complexos precisam ser transformadas em táteis, já que por outros meios - legenda, audiodescrição, etc, correm o risco de serem ineficazes ou insuficientes. Exemplos disso são mapas, gráficos, formas abstratas, geometria, corpo humano e mesmo "qualquer tipo de composição gráfica que carece de uma visualização com mais completude do que uma descrição verbal ou por Braille [...]" (Sanches, 2018, p. 37).

\section{Modelo de tradução}

Foi pensando sobre o planejamento, tradução e necessidade das imagens táteis que o modelo de tradução foi criado (link para download ao final do artigo). Este modelo é um documento digital, de dez páginas, cujo objetivo é auxiliar no desenvolvimento de imagens táteis impressas em 3D. Com ele, é possível decidir se é necessário que a imagem se traduza em tátil e, em caso positivo, entrega ao usuário uma série de recomendações sobre como realizar esta tradução. Foi elaborado para se utilizar juntamente com profissionais da Educação, tornando assim a experiência dos estudantes cegos mais acessível e inclusiva, independente de qual disciplina a imagem proceda.

O processo de criação deste modelo foi iterativo, passando por uma proposição inicial, testes com designers e testes de compreensão com cegos, até chegar em sua versão final. 


\section{Proposição inicial}

Para se estruturar a primeira versão do modelo, investigou-se na literatura quais eram as recomendações, diretrizes e boas práticas para o planejamento e tradução de imagens estáticas em imagens táteis, em especial as que utilizavam impressão 3D como meio produtivo. Ao total, foram utilizadas nove referências para a constituição de um quadro de recomendações (Figura 1).

Figura 1: referências utilizadas para o quadro de recomendações (usado com a permissão de Sanches [2018]).
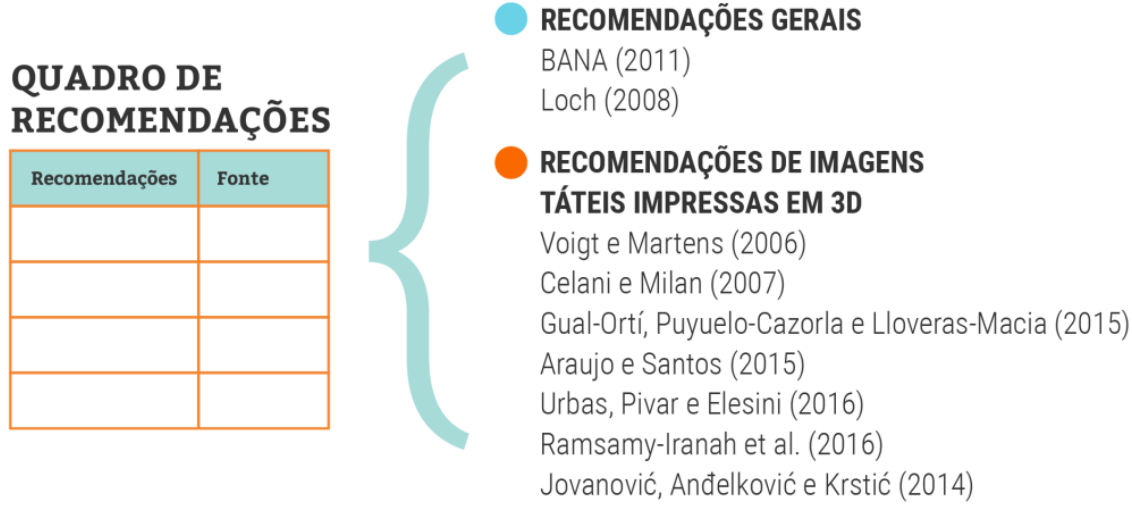

As recomendações foram compiladas e divididas em quatro categorias - variáveis táteis, composição da imagem tátil, simplificação e, aspectos físicos da imagem e usuários (para mais detalhes, ver referência Sanches [2018]). Aliado a estas recomendações, utilizou-se também o framework de análise gráfica de Engelhardt (2002) - que serviu de estrutura, um fluxograma de decisão e exemplos de texturas e linhas utilizadas em imagens táteis (Figura 2), formando assim o modelo de tradução em sua versão inicial.

Figura 2: composição do modelo inicial (usado com a permissão de Sanches [2018]).

\section{COMPOSIÇÃO DO \\ MODELO DE TRADUÇÃO}

(versão inicial - teórica)

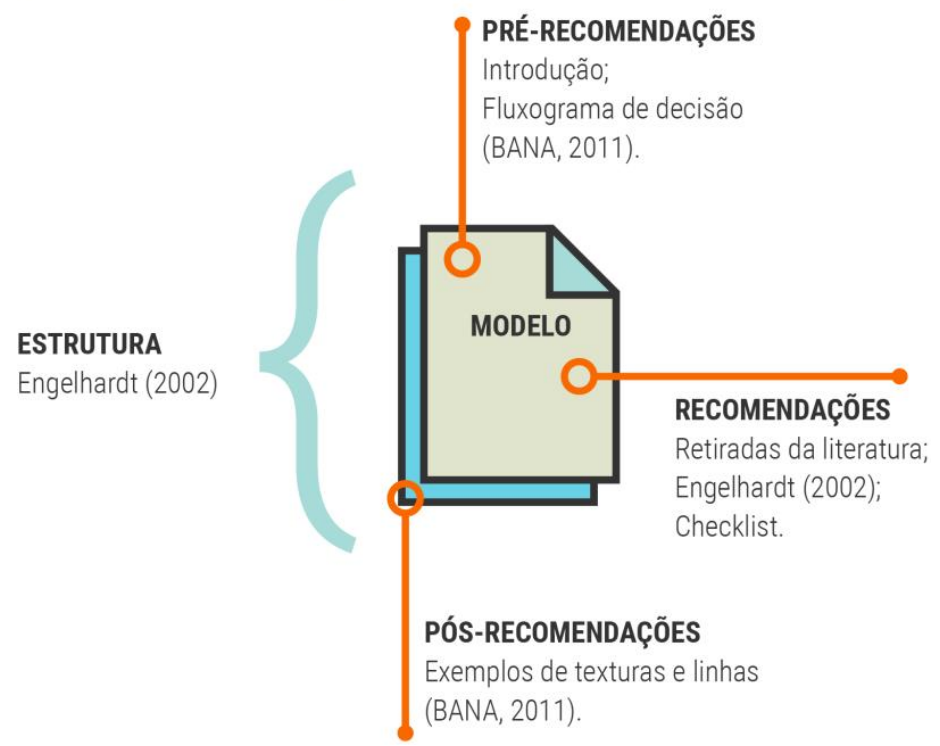




\section{Testes com designers}

Neste momento, o documento contava com seis páginas, seguindo estrutura da figura anterior. Em seguida, o primeiro teste do modelo foi realizado com designers, a fim de obter um feedback dos potenciais usuários. O objetivo era verificar falhas, as dificuldades no uso e sugestões de melhoria. O teste consistiu em utilizar o modelo de tradução para criar uma imagem tátil do mapa do Brasil. Aos três designers participantes, todos com experiência em modelagem 3D, foi fornecido uma cópia do modelo e o mapa estático. O software para modelagem ficou a critério de cada participante. O detalhamento do teste com os designers foi publicado anteriormente em Sanches, Macedo \& Bueno (2017).

Ao final do teste, as informações coletadas foram transformadas em novas informações para o modelo, conforme figura 3.

Figura 3: composição do modelo intermediário (usado com a permissão de Sanches [2018]).

\section{COMPOSIÇÃO DO MODELO DE TRADUÇÃO \\ (segunda versão - teste com designers)}

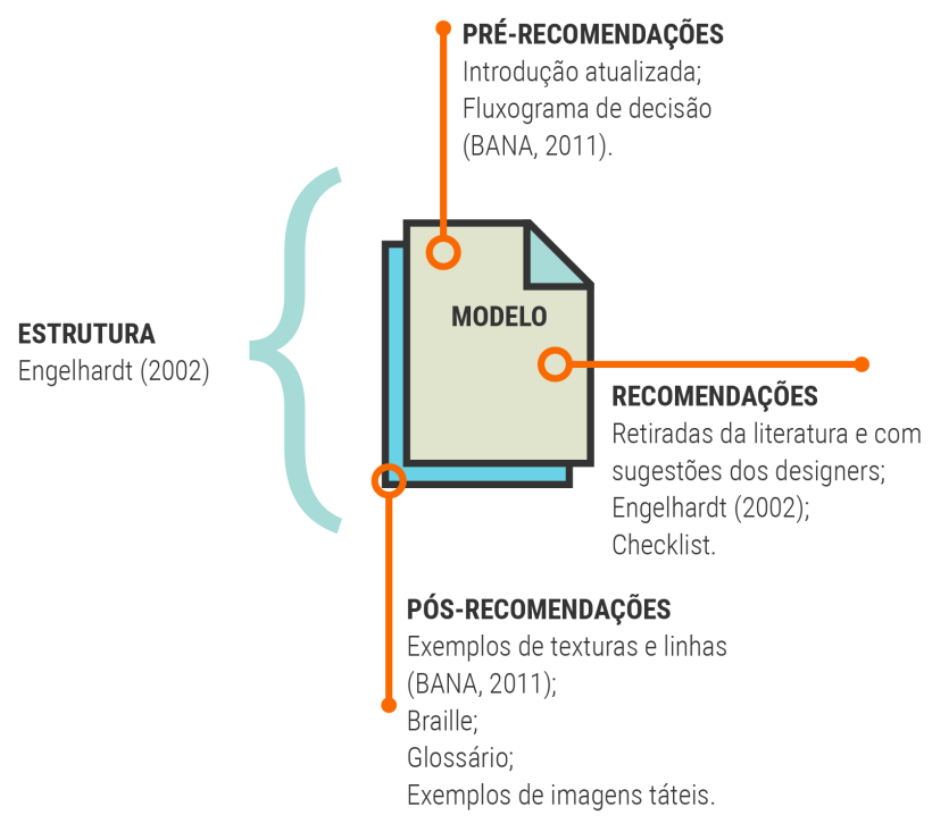

A partir desta segunda versão do modelo de tradução, a pesquisa seguiu para uma nova avaliação, desta vez, o utilizando para criar imagens táteis impressas em 3D e testá-las com cegos. O detalhamento do percurso de escolha das imagens, impressão e testes são descritos a seguir.

\section{Impressão 3D de mapas táteis}

Como dito anteriormente, o modelo de tradução de imagens estáticas em imagens táteis foi pensado para se utilizar com qualquer imagem estática, independente da disciplina - História, Geografia, Física, Biologia, etc. -, desde que haja demanda para tal. A fim de se manter uma unidade e por razões de escopo, a disciplina de Geografia foi escolhida para se realizarem os testes. Dentro da disciplina, apenas os mapas foram considerados.

Engelhardt (2002) categoriza os tipos de representações gráficas e, dentre estas, são quatro os tipos de mapa: mapa [geográfico], mapa de rotas, mapa estatístico e mapa estatístico de rotas. Estas categorias foram utilizadas para elencar os quatro mapas a serem traduzidos e 
impressos em 3D. O repositório Dia a Dia Educação (mantido pela Secretaria de Educação do Estado do Paraná) foi escolhido para prover os mapas. Nele, foram encontrados na disciplina de Geografia um total de 177 mapas do Brasil e do mundo, e 67 mapas do Paraná. Ainda sob a justificativa de se manter uma unidade de informação, foram selecionados quatro mapas do Estado do Paraná (Figuras 4, 5, 6 e 7).

Figura 4: mapa das regiões geográficas do Paraná (usado com a permissão de Sanches [2018 citado por SEED, 2017]).

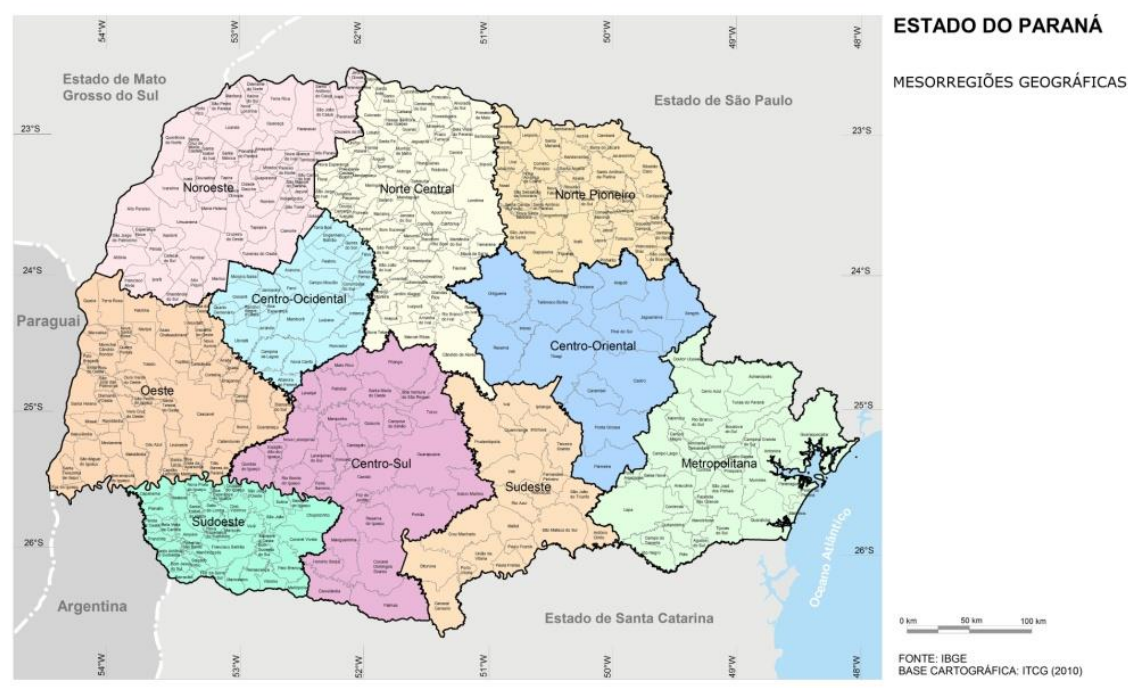

Figura 5: mapa da temperatura média anual do Paraná (usado com a permissão de Sanches [2018 citado por SEED, 2017]).

\section{Temperatura Média - Anual}

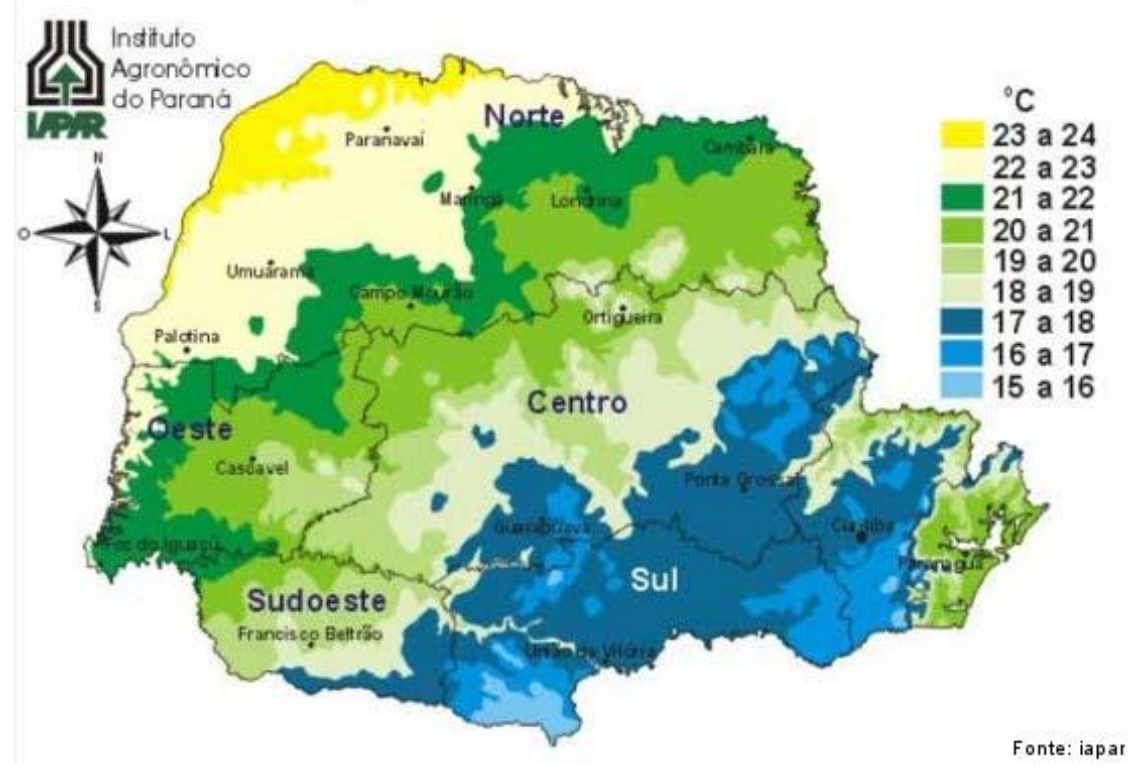


Figura 6: mapa das principais rodovias do Paraná (usado com a permissão de Sanches [2018 citado por SEED, 2017]).

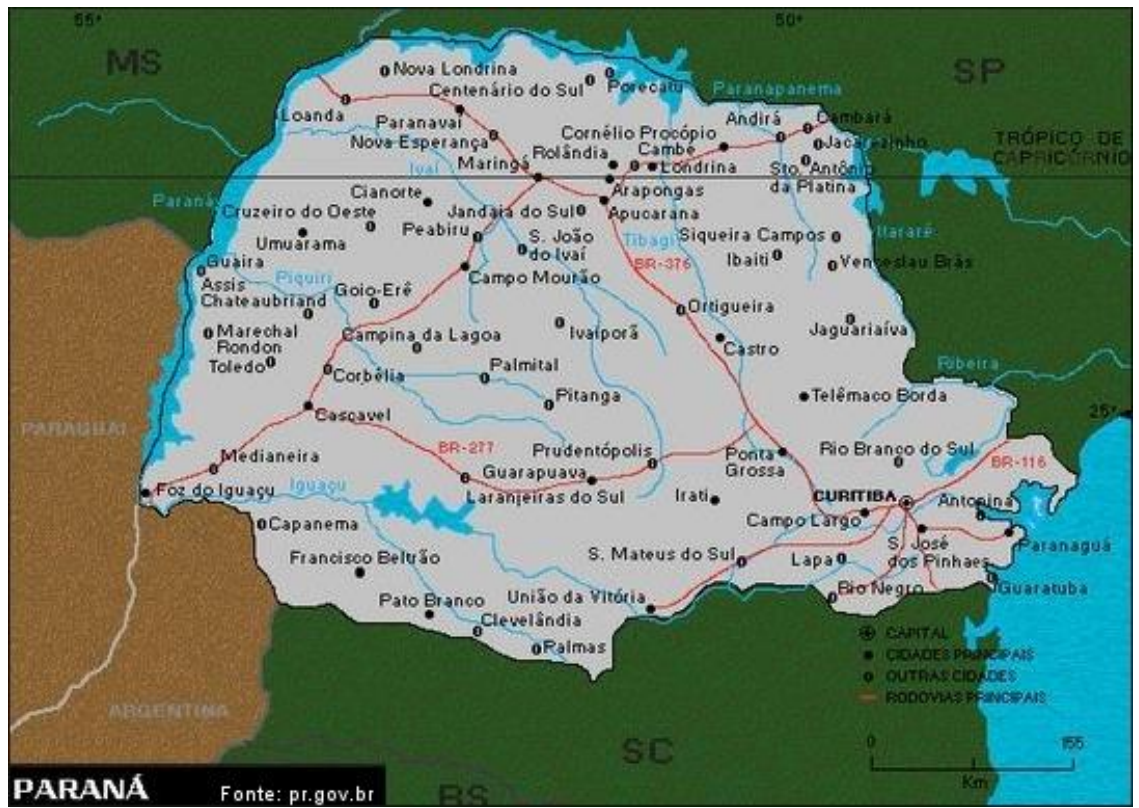

Figura 7: mapa das altitudes e estradas do Paraná (usado com a permissão de Sanches [2018 citado por SEED, 2017]).

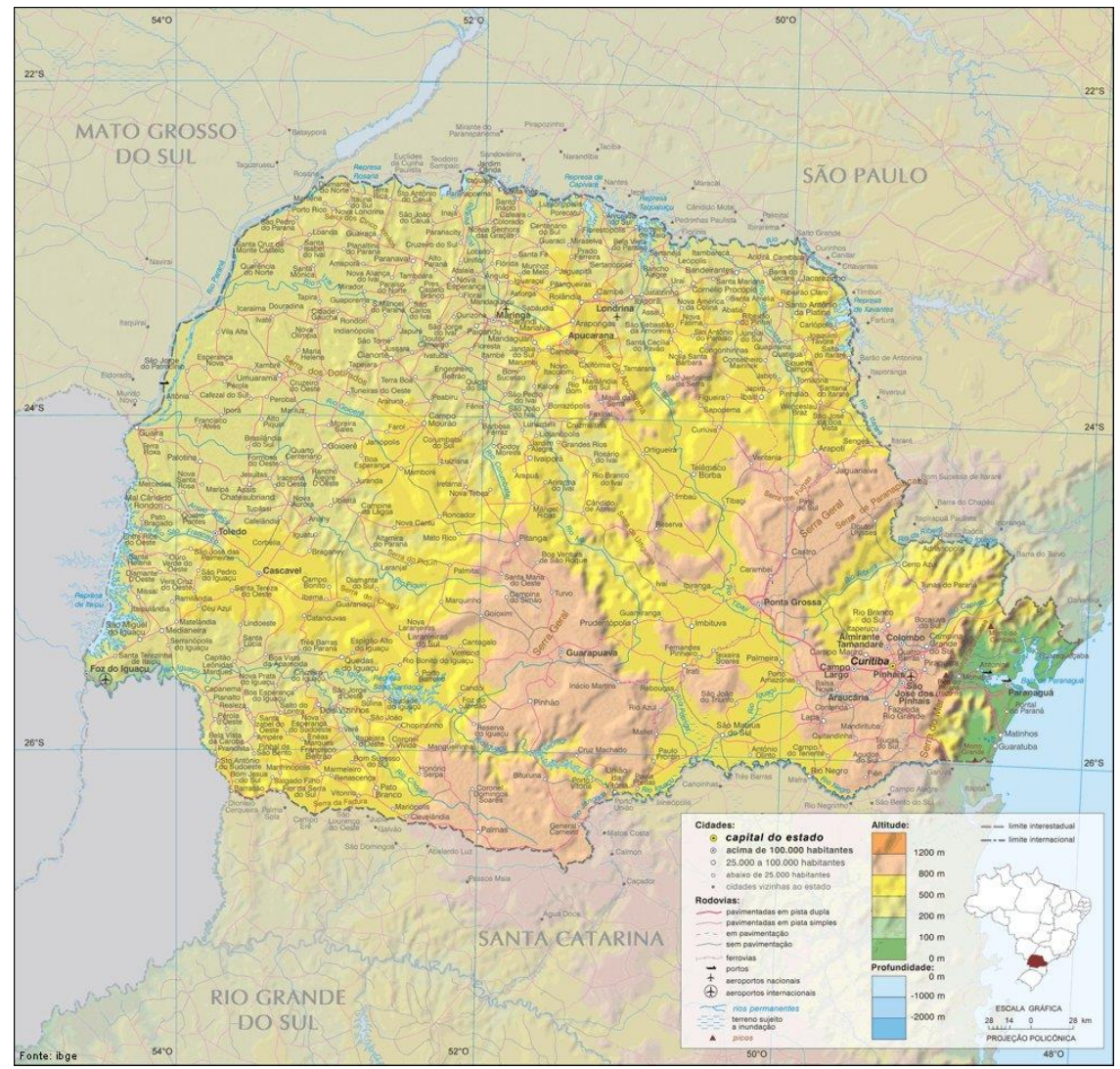

Após a seleção, quatro cópias do modelo de tradução foram impressos e preenchidos, e em seguida os mapas foram modelados digitalmente. Ao final, os mapas táteis foram impressos

Anais do 9o Congresso Internacional de Design da Informação | CIDI 2019 
por impressora 3D de tecnologia Fused Deposition Modelling (FDM), com material plástico PLA. A breve linha do tempo a seguir sintetiza as três etapas com maiores detalhes (Figura 8).

Figura 8: síntese das etapas de tradução da imagem estática em imagem tátil (usado com a permissão de Sanches $1[2018])$.

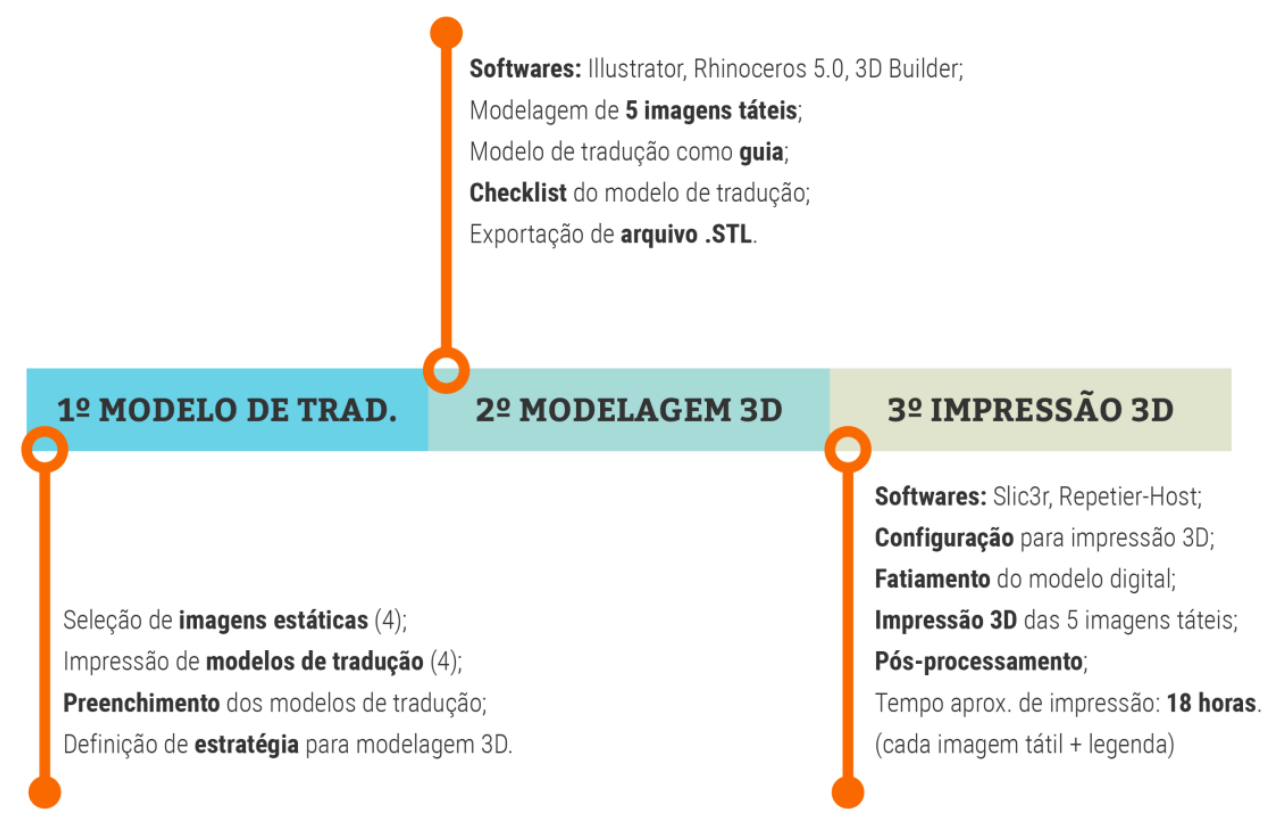

Nota-se, pela figura anterior, que foram cinco mapas táteis impressos. Isso ocorreu, pois o mapa de altitudes e estradas do Paraná (mapa estatístico de rotas) era complexo para um mapa tátil só, sendo preciso dividi-lo em dois. A seguir, as figuras 9, 10,11, 12 e 13 apresentam o resultado final.

Figura 9: mapa geográfico tátil (usado com a permissão de Sanches [2018]).

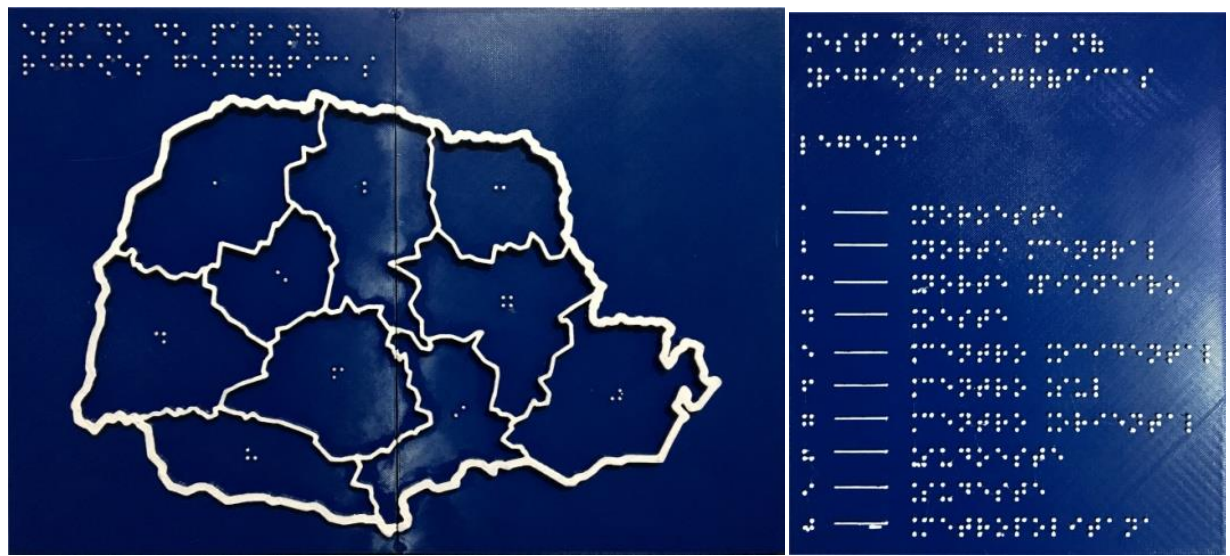


Figura 10: mapa estatístico tátil (usado com a permissão de Sanches [2018]).

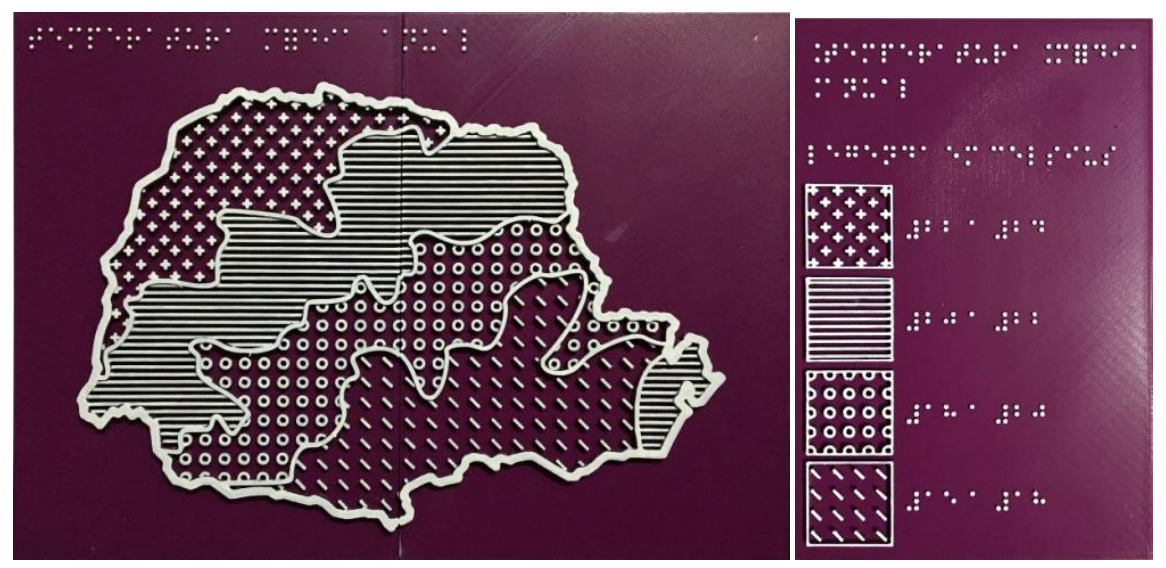

Figura 11: mapa de rotas tátil (usado com a permissão de Sanches [2018]).
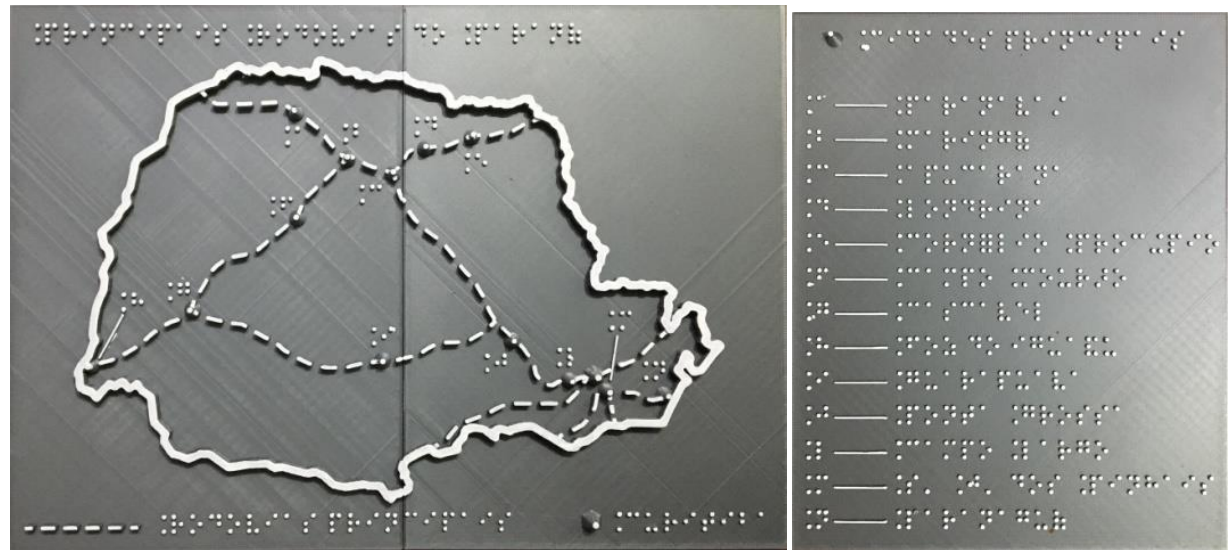

Figura 12: mapa estatístico de rotas tátil - parte 1 (usado com a permissão de Sanches [2018]).

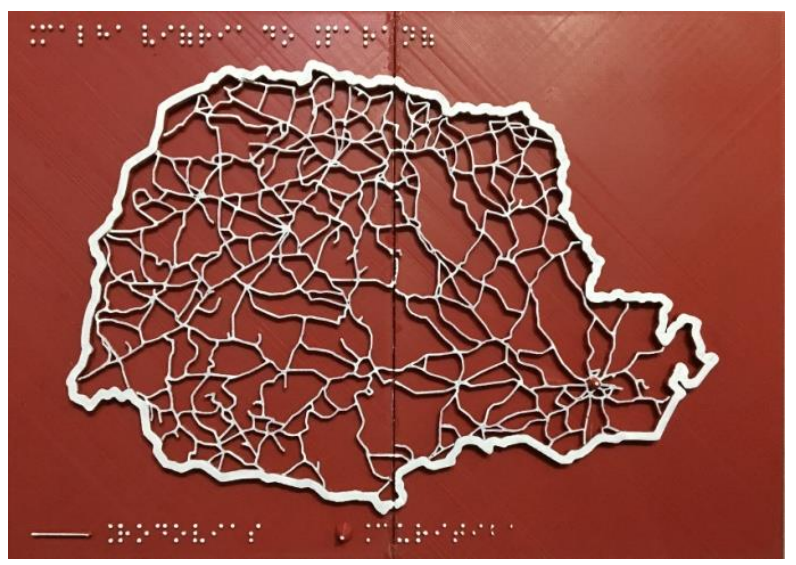

Anais do 9 Congresso Internacional de Design da Informação | CIDI 2019 
Figura 13: mapa estatístico de rotas tátil - parte 2 (usado com a permissão de Sanches [2018]).

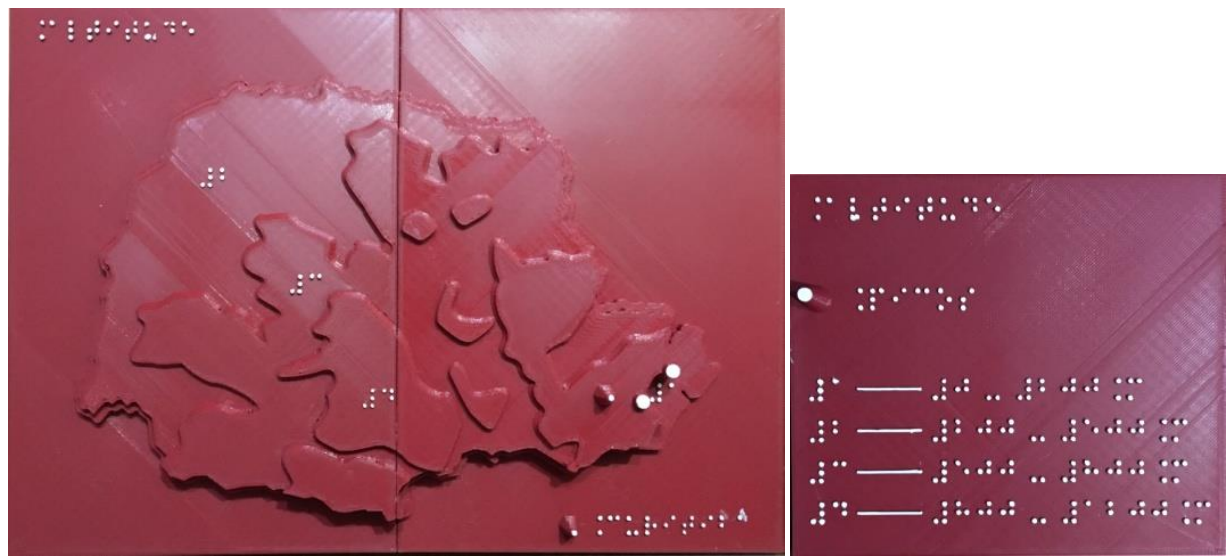

O próximo tópico discorre sobre os testes de compreensão realizados com os cegos, utilizando estes mapas impressos em 3D.

\section{Teste de compreensão}

Estruturou-se um teste de compreensão destes mapas táteis, com o objetivo de avaliar se o modelo de tradução gerou requisitos adequados e suficientes para a compreensão do conteúdo das imagens. O teste foi dividido em duas etapas: (1) teste piloto, com dois cegos, para ajustes no protocolo e; (2) teste de compreensão principal com outras oito pessoas cegas.

Para a seleção dos voluntários, os seguintes critérios foram adotados: cegos (congênitos ou adquiridos), alguma experiência com imagens táteis e também alguma experiência com mapas, cursando ou tendo finalizado o Ensino Fundamental ou Médio. Critérios de idade e gênero não foram adotados. Todos sabiam ler Braille. Os perfis dos voluntários estão resumidos na figura 14.

Figura 14: Perfil dos voluntários (usado com a permissão de Sanches [2018]).

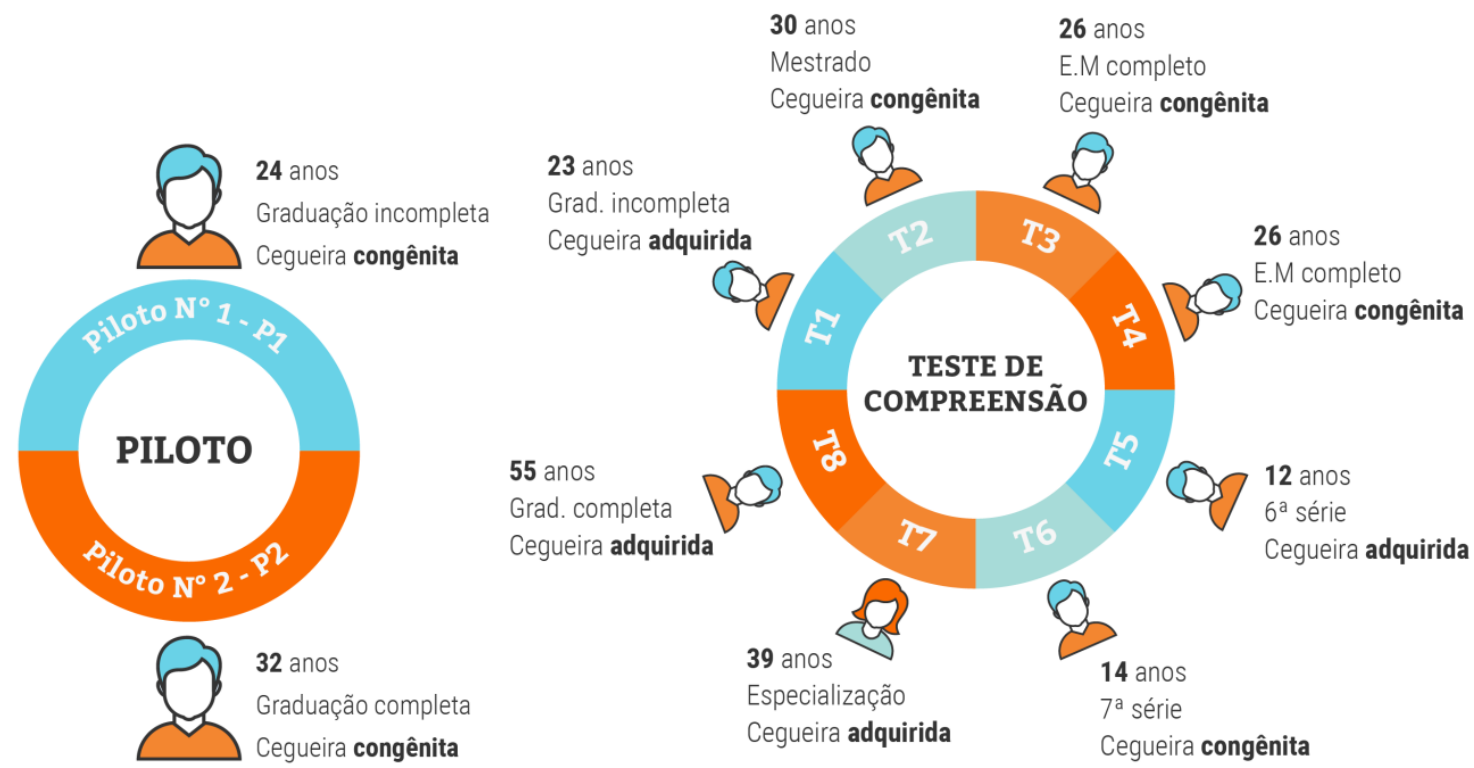


Para manter a identidade anônima, códigos foram usados para substituir os nomes dos voluntários, sendo P1 e P2 para os que participaram do piloto, e T1, T2, T3, T4, T5, T6, T7 e T8 para os que participaram apenas do teste de compreensão principal. Os procedimentos para coleta de dados foram: o uso de gravação de vídeo (apenas das mãos); think aloud e entrevista semi-estruturada (gravados em áudio).

O protocolo para o teste piloto consistia, resumidamente, em dois objetivos: testar as imagens táteis impressas em 3D e testar o protocolo; além do detalhamento do procedimento a ser seguido. Os dois testes realizados tinham uma única diferença: $\mathrm{P} 1$ não recebeu nenhum tipo de contexto sobre as imagens táteis, enquanto P2 recebeu breves explicações sobre cada uma. Esta diferença serviu para checar a melhor abordagem.

As principais dificuldades mencionadas pelos voluntários ou observadas foram:

- Dificuldade em associar letras Braille com as regiões demarcadas;

- Falta de indicadores por onde começar a leitura;

- Tamanho pequeno para o mapa geográfico e mapa estatístico de rotas;

- Dificuldade de compreender as legendas que estavam localizadas abaixo do mapa;

- Informações excessivas;

- Difícil contextualizar o mapa do Paraná em um âmbito brasileiro;

- Texturas parecidas;

- Dificuldade em acessar pontos mais baixos no mapa

- Espaçamento de algumas palavras em Braille deixou a desejar.

Já os pontos positivos mencionados foram:

- Braille compreensível e perceptível;

- Positivo manter o mesmo leiaute em todas as imagens táteis;

- Elevações diferentes foram fundamentais para a compreensão.

Ao mesmo tempo, soluções foram mencionadas pelos dois voluntários, que por vezes já eliminaria os problemas acima mencionados:

- Usar siglas em Braille ao invés de letras em ordem alfabética;

- Instruir como se deve começar a leitura do mapa;

- Aumentar o tamanho dos mapas;

- Inserir referências espaciais do que há ao redor do mapa do Paraná.

Notou-se que P1, que não teve contexto nenhum sobre os mapas táteis, teve mais dificuldades do que P2. Portanto, decidiu-se ajustar o protocolo de testes para que houvesse uma explicação padronizada para todos os participantes, como por exemplo:

Essa imagem mostra a divisão do Estado do Paraná em 10 regiões geográficas, que estão indicadas por letras em Braille. O objetivo é compreender a divisão e conhecer os nomes das regiões. Acima, o Estado de São Paulo. Abaixo, o Estado de Santa Catarina. Ao lado direito, o oceano. E ao lado esquerdo, Mato Grosso do Sul, Paraguai e Argentina (Sanches, 2018, p. 115).

Além disso, também se incluiu no protocolo uma pergunta específica para cada imagem, pedindo para que localizassem uma cidade, região ou um relevo, por exemplo.

Feito isso, os oito voluntários cegos participaram dos testes de compreensão, de forma individual e em local confortável aos mesmos (Figura 15). 
Figura 15: voluntários lendo mapas táteis (usado com a permissão de Sanches [2018])

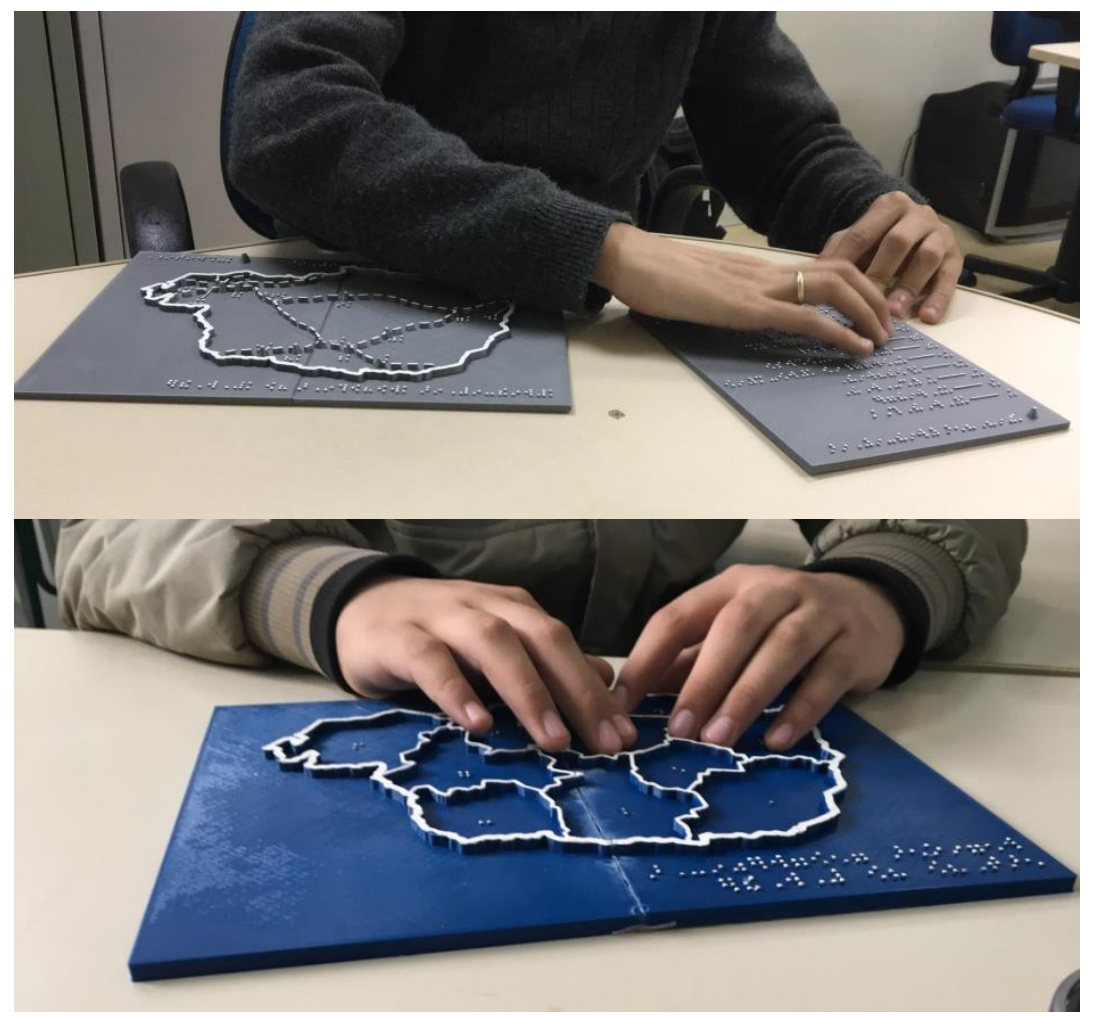

Em geral, os resultados foram positivos em relação à leitura dos mapas e a aceitação do suporte (impressão 3D em PLA).

As principais dificuldades encontradas durante os testes de compreensão foram:

- Confundir a letra Braille A com o número 1;

- Texturas parecidas;

- As legendas abaixo dos mapas eram ignoradas ou confundidas como sendo parte do mapa;

- O símbolo do hífen foi confundido como um sinal de subtração;

- Dificuldade em acessar pontos mais baixos no mapa.

Enquanto isso, os pontos positivos encontrados foram:

- Braille compreensível e perceptível;

- Gostaram da experiência de ler mapas impressos em 3D;

- Tamanho dos mapas adequados, em geral;

- Positivo manter o mesmo leiaute em todas as imagens táteis;

- Legendas adequadas.

Por fim, algumas sugestões de melhoria foram:

- Evidenciar com mais nitidez a capital de outras cidades, na legenda ou no mapa;

- Afastar os rótulos em Braille dos cantos em relevo;

- Indicar nomes das rodovias, que foram omitidas;

- Ter um professor ou tutor junto, para explicar o mapa durante a leitura;

- Ter mais cuidado na escolha das texturas.

Com todos os dados dos testes tabulados e analisados, o próximo passo foi transformar as dificuldades e sugestões em novas recomendações para o modelo de tradução, em um esforço de fazê-lo mais claro, objetivo e menos passível de erros. Os problemas e sugestões similares

Anais do 9ำ Congresso Internacional de Design da Informação | CIDI 2019 
foram combinados. Já outros não foram incorporados ao modelo, pois tratavam-se de sugestões que extrapolavam o âmbito do modelo, como por exemplo, a inserção de um professor. O processo é exemplificado pela figura 16.

Figura 16: processo de transformação de problemas e sugestões em recomendações (usado com a permissão de Sanches [2018]).

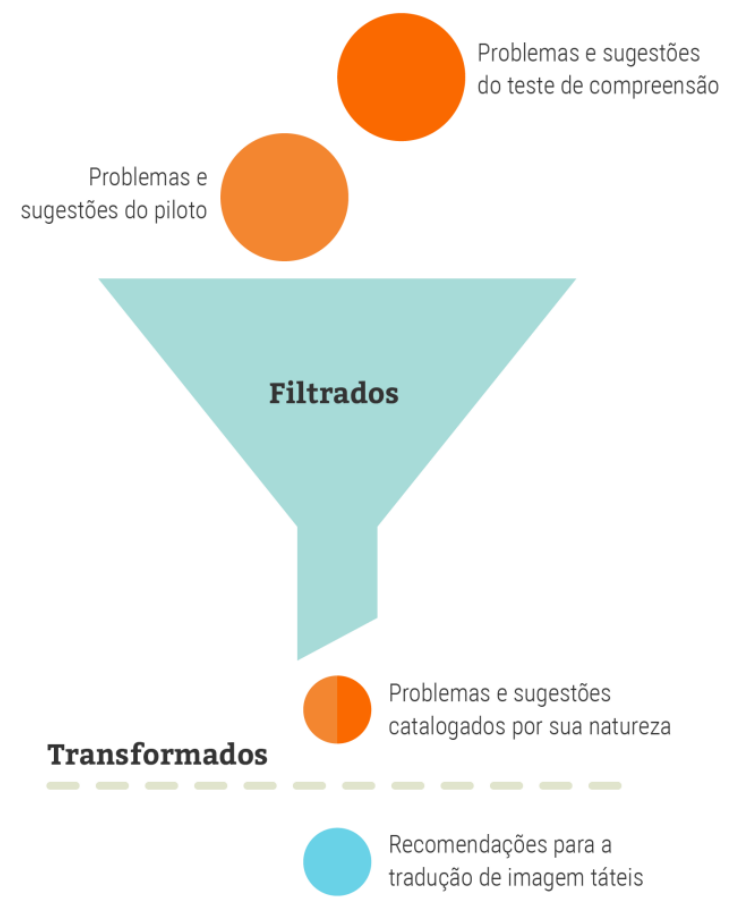

Ao total, foram 29 problemas e sugestões tabulados, transformados em 13 novas recomendações, que foram incorporadas no modelo de tradução. Assim, o modelo tomou sua forma final, após passar por alterações advindas dos testes com os designers e os testes de compreensão. A estrutura final é representada na figura 17. 
Figura 17: composição do modelo final (usado com a permissão de Sanches [2018]).

\section{COMPOSIÇÃO DO MODELO DE TRADUÇÃO \\ (versão final)}

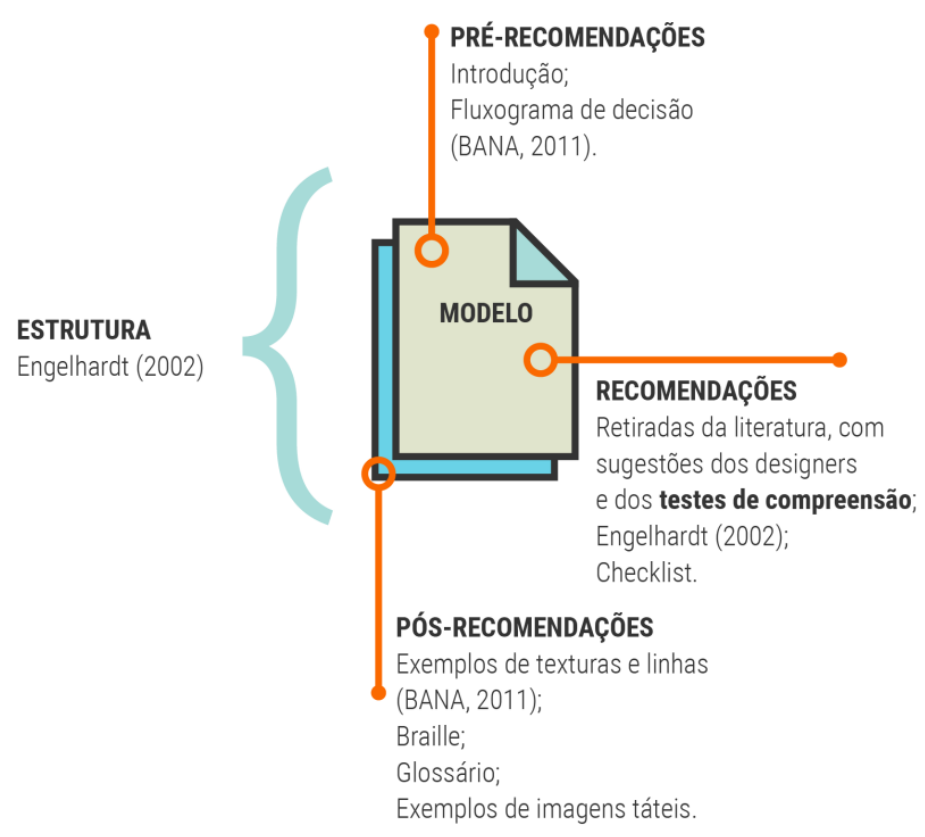

O modelo de tradução de imagens estáticas em imagens táteis pode ser encontrado para download através do link: https://goo.gl/2NDJ8M.

\section{Considerações finais}

Este artigo teve como objetivo apresentar a modelagem e impressão 3D de mapas táteis, a partir de um modelo de tradução, e discorrer sobre o teste de compreensão realizado com eles. Para tal, trouxe um breve tópico sobre percepção tátil e imagens táteis, depois demonstrou como o modelo de tradução foi concebido e testado com designers - mais detalhes em publicação anterior (Sanches, 2017). Em seguida, discorre sobre o uso do modelo para traduzir quatro mapas estáticos em mapas táteis, a serem impressos em 3D. Após mostrar o resultado dos mapas táteis, detalha o teste de compreensão realizado com dez voluntários cegos. Os resultados foram transformados em novas recomendações para o modelo, que foi atualizado e disposto em um link para download no tópico anterior.

O artigo mostrou, além disso, um dos resultados possíveis da aliança entre acessibilidade e design de informação, tanto em um conceito abrangente - 0 de solucionar a necessidade informacional de pessoas cegas na Educação através de imagens táteis, quanto ao uso do autor Engelhardt (2002) como parte do desenvolvimento do modelo de tradução.

Indica-se que este modelo de tradução de imagens estáticas em imagens táteis é um potencial material para ser aplicado em contextos reais de sala de aula, institutos e salas de recursos, abrindo também possibilidades de pesquisas futuras - como, por exemplo, aplicação em outros tipos de imagem além de mapas e a reformulação do teste de compreensão com o modelo atualizado.

Por fim, enfatiza-se a testagem dos mapas táteis como importante etapa na validação do modelo de tradução, visto que foi o momento em que os participantes perceberam, interpretaram e compreenderam a informação gerada através da tradução tátil - verificando a aplicabilidade do projeto de design da informação. 


\section{Agradecimento}

Agradecimentos a Coordenação de Aperfeiçoamento de Pessoal de Nível Superior (CAPES), pela bolsa de estudos e ao Programa de Pós-Graduação em Design da Universidade Federal do Paraná (UFPR).

\section{Referências}

Duarte, M. L. B. (2011). Desenho infantil e seu ensino a crianças cegas: razões e métodos. Curitiba: Insight.

Engelhardt, Y. (2002). The language of graphics: a framework for the analysis of syntax and meaning in maps, charts and diagrams. Amsterdam: University of Amsterdam.

Gruenwald, L. (2014). Impressão 3D: lendo imagens através do tato. Revista nacional de reabilitação - reação.

Gual, J., Puyuelo, M. \& Lloveras, J. (2014). Three-dimensional tactile symbols produces by 3D printing: improving the process of memorizing a tactile map key. British Journal of Visual Impairment, pp. 263-278.

Horn, R. (1999). Information design; emergence of a new profession. Em R. E. Jacobson, Information design. Cambridge: MIT Press.

IBGE (2010). Censo demográfico 2010: características gerais da população, religião e pessoas com deficiência. Disponível em: <https://bit.ly/2xQH3IB>. Acesso em: 07 jul. 2019.

IID (2019). What is information design. Disponível em: <https://bit.ly/329NeEw>. Acesso em: 26 mar. 2019.

Loch, R. E. N. (2008). Cartografia tátil: mapas para deficientes visuais. Portal da Cartografia, pp. 35-58.

Mantoan, M. T. E. (2003). Inclusão escolar: o que é? por quê? como fazer?. São Paulo: Moderna.

Nogueira, R. E. (2007). Padronização de mapas táteis: um projeto colaborativo para a inclusão escolar e social. Ponto de Vista, pp. 87-111.

NCSU (1997). The 7 principles of universal design. Disponível em: <https://bit.ly/2HPZTlv>. Acesso em: 27 mar. 2019.

ONU (2015). Transforming our world: the 2030 agenda for sustainable development. Disponível em: <https://bit.ly/1Epf648>. Acesso em: 01 jul. 2019.

ONU (2016). The invisibility of disability. Disponível em: <https://bit.ly/2YuxUjn>. Acesso em: 01 jul. 2019.

ONU (2019). Disability inclusive Sustainable Development Goals. Disponível em: <https://bit.ly/2Yt737z>. Acesso em: 01 jul. 2019.

Sanches, E. C. P., Macedo, C. M. S. \& Bueno, J. (2017). Imagens táteis tridimensionais: um modelo para a tradução tátil a partir de imagens estáticas bidimensionais. InfoDesign, pp. 234-252.

Sanches, E. C. P. (2018). Modelo de tradução para acessibilidade de imagens estáticas de objetos de aprendizagem através de impressão tridimensional. Dissertação (Mestrado). Curitiba, Brasil: Universidade Federal do Paraná.

Sassaki, R. K. (2010). Inclusão: construindo uma sociedade para todos. Rio de Janeiro: WVA.

Twyman, M. (1982). The graphic presentation of language. Information Design Journal, pp. 222. 
Sanches, E. C. P. \& Bueno J.|Modelo de tradução de imagens estáticas em imagens táteis: avaliação e testagem com mapas táteis

Valente, D. (2009). Os diferentes dispositivos de fabricação de imagens e ilustrações táteis e as possibilidades de produção de sentido no contexto perceptivo dos cegos. Revista Educação, Artes e Inclusão, pp. 59-82.

Waller, R. (2016). Transformational information design. Em P. Oven \& C. Požar, Disability On information design. Ljubljana: The Museum of Architecture and Design.

\section{Sobre as autoras}

Emilia Christie Picelli Sanches, Me. e doutoranda, UFPR, Brasil <emilia.ecps@gmail.com> Juliana Bueno, Dra., UFPR, Brasil <julianabueno.ufpr@gmail.com> 